chemistry, concerned not with the outer layers of the atom but with the nucleus itself. The transmutations of one element into another involves adding or subtracting a particle, charged or uncharged, to or from the nucleus, and this may be effected in many cases by bombardment with foreign particles. A few of these particles may enter the nucleus, and this may sometimes lead to the emission of a particle from the nucleus itself. The first of such transmutations was accomplished in 1919, when nitrogen was disintegrated by $\alpha$-particle bombardment with the liberation of fast protons. More recently, a new type of disintegration has been discovered in which a neutron is emitted. In these cases the residual nucleus in the transformations is stable. In the cases investigated by $\mathrm{M}$. and Mme. Curie-Joliot, an artificial radioactive element is formed by bombarding a light element with $\alpha$ particles. Fermi and his collaborators have found that a very large number of elements can be disintegrated by neutron bombardment, giving artificial radioactive elements. The neutron, on account of its lack of charge, can penetrate the heavy nuclei when $\alpha$-particles would be turned back. Finally, Lord Rutherford directed attention to the accomplished production of nuclear disintegration, using bombarding particles artificially accelerated by high voltages instead of the particles emitted from natural radio-elements.

\section{Science and Road Traffic}

In his lecture before the British Science Guild on December 19, Col. Mervyn O'Gorman discussed the application of science to the problems of road traffic. Road traffic, he said, is not replaceable by other distributive agencies, and its prosperity is indeed advantageous to them. The magnitude of motor transport as an industry is such that it has more employees, involves more capital wealth, and pays larger taxation to the State than almost any other industry in England. Inprovement which is being, and must be, sought in safety of distribution by road involves getting the largest amount of road distribution achieved per single accident. The business of evolving the necessary instruments, the analytical methods, the interpretation of data, and similar work on the accident ratio is the proper function of science, especially physics, mechanics, mathematies, chemistry, geology, metallurgy, statistics, physiology, psychology, etc. A committee should be formed to advise and undertake research, and it should not contain road interests (financial or professional) and it should receive all the specific 'road and traffic' information that it needs from the Ministries of Transport and of Health, the Home Office and from witnesses. Following the precedent of the successful Aeronautical Research Committee at its foundation in 1908 , it should report direct to the First Lord of the Treasury. Its members should be paid, and should all be scientific men, preferably nominated by the Royal Society in conjunction with the Department of Scientific and Industrial Research. The committee having been formed, it should be free to formulate and verify its own theories in the study of safe traffic flow, economic flow, pedestrian flow, etc., these being the frameworks of various long-range researches.

\section{Maternal Mortality}

SIR Huton Young, the Minister of Health, received on December 11 a deputation from the Maternal Mortality Committee. Mrs. H. J. Tennant, introducing the deputation, said that it represented more than 3,000,000 women and was the outcome of a meeting on the subject of maternal mortality held in November. Mrs. Barton said that malnutrition, though not a primary cause, is a contributing factor to maternal mortality, and she fears that the block grant system of Exchequer grants is less effective in stimulating local authorities than the former percentage grants. Lady Barrett dealt with the question of ante-natal care, and the necessity of improving the training of doctors and midwives. Miss Gregory considers that midwives ought to have a two- or three-year course in a first-class hospital. Other speakers stressed the importance of maternity and child welfare services. The Minister, in reply, said that the problem of maternal mortality is giving him grave concern. The maternity and child welfare services of local authorities are being steadily developed, and he considers that no financial check has been placed upon them by the alteration in the grant system. There is no evidence that there is any close relation between malnutrition and a high maternal mortality rate. Nevertheless, the conditions in depressed areas are such as to give rise to anxiety, and the position is receiving the close attention of the administration. $\mathrm{He}$ outlined measures that are being taken to improve maternity and child welfare services throughout Great Britain, and alluded to special inquiries and investigations that are being made in districts where the maternal mortality rate is abnormally high.

\section{Further Tests of the Medium Rudi Schneider}

IN the Proceedings of the Society for Psychical Research for October is published a further report on the alleged psychic phenomena occurring in the presence of the medium Rudi Schneider. Under the joint authorship of Mr. T. Besterman and Mr. O. Gatty, the paper describes an attempt to look for confirmation of the infra-red phenomena previously reported, and generally to conduct tests by instrumental means. As an example of the kind of methods to be used in experimental work with the so-called physical phenomena, the report seems to be a step in advance, and the results suggest that through such instrumental means a better idea of the nature of the phenomena may be obtained. Generally speaking, the present results were negative. The interruption of the infra-red rays as previously reported by Dr. Osty in Paris and by others in Great Britain received no confirmation, in spite of a series of careful observations; and through the help of of Dr. C. G. Douglas it was ascertained that the medium's breathing, which was considered of sufficient interest to reproduce in a recent series of talks 
broadcast by the B.B.C., had nothing supernormal about it, being merely somewhat shallow and quite normal considering the muscular movements made by the medium during the trance. Thus the report as a whole contains no good evidence that Rudi Schneider possesses supernormal powers ; and further controversy concerning the case can therefore be post. poned until positive evidence is adduced based upon the kind of instrumental methods outlined in the present report.

\section{National Institute of Industrial Psychology}

THE annual report of the National Institute of Industrial Psychology appears in the Human Factor, vol. 8 , No. 12. The Institute is approaching a critjcal period in its career, when lack of funds may seriously curtail its research work. The report stresses this fact, and describes the work accomplished along various lines, touching on investigations in factories, warehouses, offices and shops, investigations of the processes of distribution, vocational guidance, research and educational work. A vocational guidance scheme has been launched in Bristol; and largescale experiments in Fife, and in Borstal institutions, have been completed this year. Researches into the possibility of simplifying and modifying tests of manual skill, and of devising tests for mathematical and linguistic ability, and the part played by rhythm in manual work are being continued. A study of the use of practical performance tests of intelligence and, on the vocational selection side, the analysis of three occupations, namely secretarial work, nursing and secondary school teaching, have been completed.

\section{Liverpool Geological Society}

THE seventy-fifth anniversary of the foundation of the Liverpool Geological Society was marked by a scientific conversazione, under the presidency of Dr. R. G. Wills, held in the Department of Geology, of the University of Liverpool, on December 11. The assembly commenced with the reading of the minutes of the first ordinary meeting of the Society in 1859, after which the Society's Medal was presented to Mr. Emil Montag, Swiss consul in Liverpool, for services rendered to the Society during his twentyfour years' active membership, his editorship, his contributions to British and Swiss geology and his work in providing facilities for study in Switzerland. Prof. H. H. Read, Herdman professor of geology in the University of Liverpool, vice-president of the Society, then delivered a short lecture on earthquakes, followed by a demonstration of the University seismograph. Dr. E. Neaverson lectured on palæontological exhibits, and there was a demonstration of rockcutting and of new maps. Amongst the exhibits on view at the conversazione was an interesting collection of fossils, new instruments and minerals, the latter including specimens of two new British minerals recently found in Scotland; chondrodite, found in association with metamorphic limestone, and stichite, found in association with ultra-basic rocks.

THE Liverpool Geological Society, which publishes an annual Proceedings, has mado many valuable contributions to geological history, and among its most distinguished members in the past were George H. Morton, one of its founders, and author of the "Geology of the Country Around Liverpool" (1863). After the Geological Survey had examined the area, a second edition of Morton's work was issued in 1891. The Rev. H. H. Higgins made valuable discoveries of fossil ferns in the Ravenshead railway cutting near Rainhill in 1870, and H. C. Beasley described the well-known labyrinthodont footprints from Storeton quarries, Cheshire, which G. H. Morton later named Cheirotherium stortonense. Despite what may be called a geological and palæontological poverty amongst the rocks of its sandstone area, the Liverpool Geological Society has kept research well to the fore in its history, and its Proceedings contain many valuable contributions to geological science.

\section{Apparatus for Photographic Reproduction}

THE reproduction of documents, drawings, etc., by photography is, of course, widely practised. It is possible by direct photographic printing to do such work without a camera. With sheets of translucent material of which only one side is used for the design or writing, such a method is capable of furnishing a paper negative which may be used for printing positive copies. The same method may be used for making readable copies which are negatives only in respect of black and white. If, however, the sheets of the original have matter on both sides, this simple method of printing is not possible, and it is necessary to use the method of 'reflex' photographic printing to make a negative, from which positive copies are made by printing through. Reflex printing consists in placing a sheet of the sensitive paper in contact with the matter to be copied, and exposing through the sensitive paper. Differential reflection from the design and its background is sufficient to give a printable image. These methods have long been known and used for the reproduction of copies of the same size as the originals. A very convenient portable apparatus comprising lamps, printing frame and automatic exposure timing device, which we have examined, has now been placed on the market by Messrs. Bornett and Co., Ltd., 7-8 Idol Lane, E.C.3. This apparatus is known as the "Rectophot Rapid Reproducer" and is made in two sizes, the smaller of which will deal with papers $13 \frac{1}{2}$ in. $\times 10$ in. ; the larger with 22 in. $\times 15$ in.

\section{Synthetic Compound with Vitamin $\mathbf{B}_{\mathbf{2}}$ Activity}

As is well known, lactoflavin induces growth in rats fed on a vitamin $\mathrm{B}_{\mathbf{g}}$ free diet. In a lecture at the Kaiser Wilhelm Institute for Medical Research in Heidelberg, Richard Kuhn, who with P. György discovered the biological activity of lactoflavin, reported that he had synthesised a compound with the same properties as lactoflavin. The synthetic substance was prepared by interaction of a suitable derivative of 1-nitro-3, 4-xylol with $l$-arabinamin, with subsequent reduction of the product formed and condensation with alloxan. $0.015 \mathrm{mgm}$. of this substance prevented hypovitaminosis in rats. This dose is of the same order of magnitude as that required for lactoflavin, whereas the corresponding 